\title{
The past and present scenario of avian influenza and its control strategy in Bangladesh: A review
}

\author{
M. Giasuddin ${ }^{1 *}$, M.Z. Ali ${ }^{1}$, M.R. Karim ${ }^{1}$, M.Z. $\operatorname{Hassan}^{1}$, M. Hasan ${ }^{1}$ and E. Islam² \\ ${ }^{1}$ National Reference Laboratory for Avian Influenza, Animal Health Research Division, Bangladesh \\ Livestock Research Institute, Savar, Dhaka-1341, Bangladesh. ${ }^{2}$ Research on FMD and PPR in Bangladesh, \\ Bangladesh Livestock Research Institute, Savar, Dhaka-1341, Bangladesh
}

\begin{abstract}
Avian influenza virus (AIV) is a pandemic thread and this year 2018 is passing the century of Spanish flu (H1N1) of 1918 when the world approximately 50 million human deaths occurred worldwide. About 1.7 million peoples become died in over Asia from 1957 to till now by the name of Asian flu (H2N2) at 1957 and Hong Kong flu (H3N2) at 1968. In Bangladesh, since first identification of Highly Pathogenic Avian Influenza (HPAI) at 2007 poultry industry faces outbreaks at a significant level in every year although human infection is uncommon. The infections spreading among all major avian species like chicken, duck, turkey, quail. On the other hand it is reported that the infection is spreading among wild birds like house crow, migratory birds and wild animals also. During first isolation the virus were in clade 2.2.2 but after several mutations over 11 years now it becomes under clade 2.3.2.1 a and circulating in environment. Government of Bangladesh decided to vaccinate against AIV in 2012 with two killed and one vector vaccine to combat the AIV that brings a satisfactory result. But from the couples of years again the incidence of AIV becomes very high and ongoing researches like sink surveillance shows 50-90\% live bird markets of Dhaka and Chattagram districts are infected. To combat the AIV it is recommended that farms should have to ensure the good quality vaccine with good farm biosecurity practice along with conventional stamping out program.
\end{abstract}

(Key words: Avian influenza virus, poultry, vaccine, infection)

\section{Introduction}

Avian influenza virus has received increasing attestation over the years, as it affects production, trade and human health. The viruses are distributed worldwide and cause serious economic losses when outbreak occurs in chickens, turkeys and other gallinaceous birds (Morin et al., 2018; Dhingra et al., 2018; Ali et al., 2015; Ali et al., 2017). The current highly pathogenic avian influenza (HPAI) H5N1 panzootic has spread from Southeast Asia since 2003 (Li et al., 2014). Bangladesh first experienced the wave of H5N1 HPAI in February 2007 (Biswas et al., 2008). About 550 outbreaks have been reported to the World Organization for Animal Health (OIE) placing Bangladesh as one of the most affected country in the world (OIE, 2018). Up to March 2018, eight human infections where seven non-fatal and one fatal cases of $\mathrm{H} 5 \mathrm{~N} 1$ influenza have been reported to WHO from Bangladesh (WHO, 2012). Outbreak situation in the country since 2017 remain quite difficult to understand and no new case have been reported except one crow mortality report to OIE at 2018. Bangladesh has no realistic evidence that the country is free from HPAI H5N1 due to several surveys and published reports confirming that the disease is now endemic in Bangladesh.

In Bangladesh avian influenza virus H5N1

*Corresponding author: mgias04@yahoo.com

Bang. J. Livs. Res. Special Vol. 21-25, 2018: P. 24-28, ISSN 1022-3851 
has been reported in multiple host species since its first outbreak at 2007 (Biswas et al., 2008). Duck, pigeon, quail, migratory birds and house crow infection has been reported previously. Several researchers also reported HPAI (H5N1) infection from Turkey which is newly introduced in poultry farming in Bangladesh. It indicates that circulating avian influenza viruses are aggressive to infect wide host range (Parvin et al., 2018).

\section{Situation of avian influenza in Bangladesh}

Since 2007 there have been at least three separate introduction of H5N1 in Bangladesh. Clade 2.2.2 viruses were fast introduced and remain dominant up to 2010 (Biswas et al., 2008). Then it becomes more devastating at 2008 as clade 2.2.2.1. Introduction of two new clades 2.3.2.1 and 2.3.4.2 along with 2.2.2 viruses found circulating in 2011 and 2012 but clade 2.3.4.2 were not found after 2012. From 2013 only 2.3.2.1a viruses remain in circulation by replacing two other clades of viruses (Figure 1) (Biswas et al., 2018; Islam, 2018). In 2017 Government of Bangladesh reported to OIE about the emergence of novel H5N6 avian influenza in Bangladesh. Phylogenetic analysis based on partial sequences of the HA gene of H5N6 subtype belonged to clade 2.3.4.4 (Samad et al., 2019). Avian influenza outbreaks in Bangladesh are endemic in nature and have a distinct seasonal pattern, most of the outbreaks occurred in winter and spring (Figure 2).

\section{Avian influenza control strategy in Bangladesh}

In 2005 Government has developed $1^{\text {st }}$ National Plan document with the help of a National multi- sectorial planning team. This national plan was provided a strategic frame work for coordinating activities within and between the various sectors and stakeholders for preparedness and response to avian and

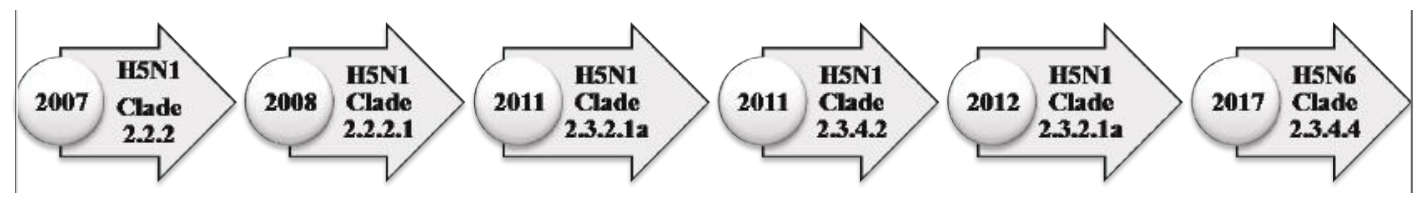

Figure 1: Genetic mutation of avian influenza in Bangladesh over time.

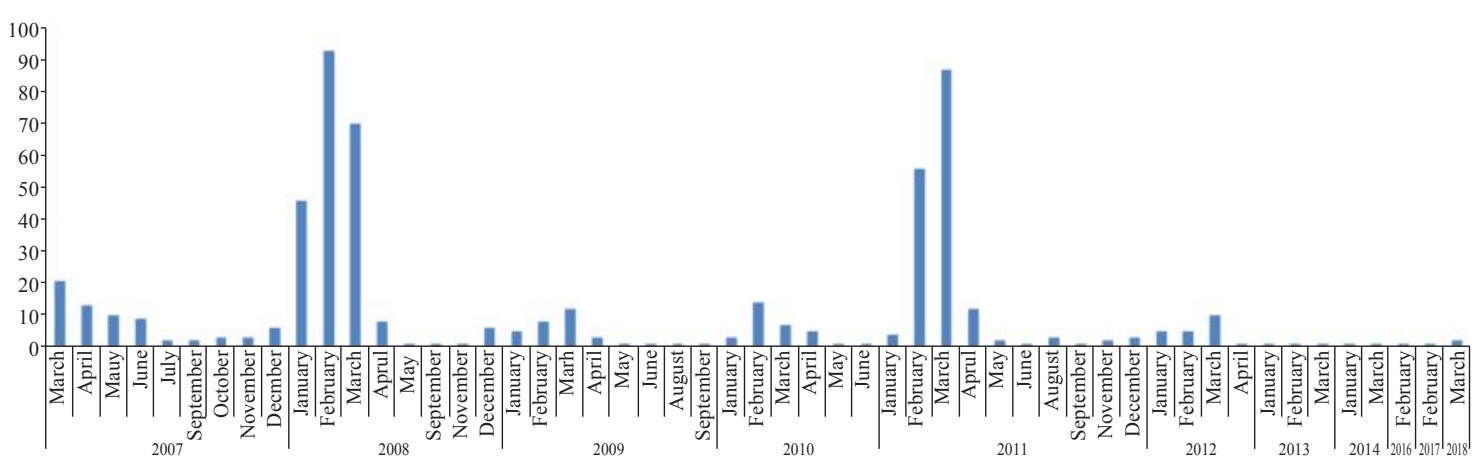

Figure 2: Total number of monthly reported HPAI outbreaks in Bangladesh 
human pandemic influenza in Bangladesh. From the first outbreak, Bangladesh try to overcome the problem by following activities.

a) Early diagnosis, reporting and rapid culling (Stamping out)

b) Decontamination of affected farms and movement control

c) Epidemiological surveillance

d) Improvement of farm biosecurity

On the incursion of HPAI in 2007, Bangladesh also adopted the policy of stamping out for the control of avian influenza. In case of infection in a commercial poultry farm all type birds, eggs and animal feed kept in the farm premises was destroyed and disposed and in case of a backyard farm same type of animals and materials kept 500 meter around the infected premise was destroyed and disposed following the SOP for stamping out procedure developed by Department of Livestock Services (DLS) (Biswas et al., 2008; 2nd AI National Plan, 2009). Quick detection and rapid response were emphasized, but delayed reporting was happened in many outbreak cases. Movement restriction was imposed but entry of infected chickens in the market have not been prevented. A novel and effective SMS Gateway based clinical surveillance was initiated with the help of FAO and found worked well. But that was not sustained due to fund constraint after completion of the project. Several trainings were arranged to build up the capacities of veterinary services in Bangladesh. There a policy of compensation for the farmers whose birds were H5N1 identified and culled. However, compensation was often delayed due to fund constraint (Islam, 2015). Now compensation activities were completely stopped. As a result the number of non-reporting HPAI case was gradually increased (Moyen et al., 2018).

But all those approach have failed to contain the spread of HPAI in Bangladesh. Poultry industry claimed the loss of more than $50 \%$ of their stock. In this regard, Government of Bangladesh decided to use vaccination as an additional tool on trial basis to combat HPAI H5N1 spread since 2012 (Shin et al., 2016). Government constituted an Expert Committee to design and supervise the trial vaccination programme and provided recommendation. In 2013 the Government of Bangladesh started vaccination against $\mathrm{H} 5 \mathrm{~N} 1$, HPAI in selected geographical regions. After receiving recommendation from expert committee in 2014, the program has been expanded to areas further of the country. The Committee set an objective, to reduce avian influenza outbreak to a level that can be responded effectively through conventional stamping out procedure (2nd AI National Plan, 2009). The vaccination trial was limited in two selected districts initially. The program was implemented through public-private partnership under the control of Department of Livestock Services (DLS). Expert committee selected two killed and one vector immune HVT-AIV vaccines.The target of vaccination were taken as considering all existing breeder stocks, day old chicks produced by the breeder farms and commercial layers. As per policy, farmers bought and vaccinate their flock with the clearance from authority and support to conduct post vaccine surveillance.

\section{Experience of AIV vaccination in Bangladesh}

Reporting of clinical outbreaks of HPAI 
(H5N1) reduced in Bangladesh after vaccination started in early 2013. Low mortality due to avian influenza in vaccinated flocks almost neglected. Surveillance in live bird market indicates the presence of HPAI (H5N1) in poultry. Other subtypes including H9N2 found dominant in commercial poultry. Farmers are now demanding for H9N2 vaccine permeation.

\section{Present status of avian influenza control in Bangladesh}

Due to lack of proper monitoring vaccination activities were failed to achieve its goal. The control of the veterinary authority on vaccination campaign has not always been as per plan. As a result, proper implementation and goal was not achieved. Several investigators reported the presence of HPAI H5N1avian influenza virus in circulation with high mortality. This information also supports the report of National Reference Laboratory for Avian Influenza (NRL-AI). Sink surveillance (conducted by DLS, NRL-AI and FAO) report shows high prevalence of $\mathrm{H} 5$ and $\mathrm{H} 9$ virus (50\% to $90 \%$ ) over the year in live bird market in Dhaka and Chittagong cities. Samples which were carried to NRL-AI also found presence of avian influenza virus in all types of poultry populations. Most of the breeder and large commercial poultry farms using government selected vaccine. Although they also face clinical problem H9 subtype with high production loss and low mortality. Some farmers discard their flock due to high production loss. NRL-AI, BLRI reported on circulation of LPAI and also HPAI in H5 vaccinated flocks. The report was stated that, avian influenza virus sub-type H5 was not shaded in the farms with good biosecurity but were shaded in $5.8 \%$ farms with moderate biosecurity and $8.1 \%$ farms with poor biosecurity. Avian Influenza virus sub-type H9 were shaded in $14.1 \%$ farms with good biosecurity, $23.5 \%$ farms with moderate biosecurity and $27 \%$ farms with poor biosecurity (Samad et al., 2017). Recently, the lab identified avian influenza virus sub-type $\mathrm{H} 5$ in $\mathrm{H} 5$ vaccinated good biosecurity farms with $\mathrm{HI}$ titer $>\log 2^{8}$. It indicates immune escape $\mathrm{H} 5$ viruses are circulating in poultry in Bangladesh (unpublished data).

\section{Conclusion}

Avian influenza is endemic in Bangladesh and has a distinct seasonal pattern. From the experience of last few years it may be concluded that vaccination is not an alternative to biosecurity and conventional stamping out approach of avian influenza control. It could be an additional tool, only if it is used thoughtfully. Stamping out approach needs to be revised and a level of compensation also important for affected farmers.

\section{References}

Ali, M.Z., Rahman, M.M., and Sultana, S. 2015. Seroprevalence of Mycoplasma gallisepticum antibody by ELISA and serum plate agglutination test of laying chicken. Veterinary world. 8(1): 9-14.

Ali, M.Z., Sultana, S., Karim, M.R., Hassan, M.Z., Yousuf, M.A., Hossen, A., ...and Rahman, M.M. 2017. Compared the effect of indirect ELISA and serum plate agglutination (SPA) test for the detection of Mycoplasma gallisepticum in chicken. International Journal of Health, Animal Science and Food Safety. 4(1): 59-66.

2nd National Avian and Pandemic Influenza Preparedness and Response Plan, Bangladesh, 2009-2011. Government of the People's Republic of Bangladesh. 2009. p. 50.

Biswas, P.K., Giasuddin, M., Chowdhury, P., 
Barua, H., Debnath, N.C. and Yamage, M. 2018. Incidence of contamination of live bird markets in Bangladesh with influenza A virus and subtypes H5, H7 and H9. Transboundary and Emerging Diseases. 65(3): 687-695.

Biswas, P.K., Christensen, J.P., Ahmed, S.S., Barua, H., Das, A., Rahman, M.H., Giasuddin, M., Hannan, A.S., Habib, M.A., Ahad, A. and Rahman, A.S. 2008. Avian influenza outbreaks in chickens, Bangladesh. Emerging Infectious Diseases. 14(12): 1909.

Dhingra, M.S., Artois, J., Dellicour, S., Lemey, P., Dauphin, G., Von Dobschuetz, S., Van Boeckel, T.P., Castellan, D.M., Morzaria, S. and Gilbert, M. 2018. Geographical and historical patterns in the emergences of novel highly pathogenic avian influenza (HPAI) H5 and $\mathrm{H} 7$ viruses in poultry. Frontiers in Veterinary Science, 5.

Islam, M.R. 2018. Molecular epidemiology of $\mathrm{H} 5 \mathrm{~N} 1$ and $\mathrm{H} 9 \mathrm{~N} 2$ avian influenza viruses in Bangladesh. Proceedings of the WVPA-BB Symposium on Avian Influenza Vaccination and Surveillance, 12 May, Dhaka, Bangladesh. Page 17.

Islam, M.R., 2015. Global and local challenges in the control of avian influenza. Proceeding of the seminar World Poultry Science AssociationBangladesh Branch. 9th International Poultry Show \& Seminar, Feb 19-21, Bangladesh, p. 5-14.

Li, X., Zhang, Z., Yu, A., Ho, S.Y., Carr, M.J., Zheng, W., ... and Shi, W. 2014. Global and local persistence of influenza A (H5N1) virus. Emerging Infectious Diseases. 20(8): 1287.

Morin, C.W., Stoner-Duncan, B., Winker, K., Scotch, M., Hess, J.J., Meschke, J.S., ... and Rabinowitz, P. M. 2018. Avian influenza virus ecology and evolution through a climatic lens. Environment International. 119: 241-249.
Moyen, N., Ahmed, G., Gupta, S., Tenzin, T., Khan, R., Khan, T., Debnath, N., Yamage, M., Pfeiffer, D.U. and Fournie, G. 2018. A large-scale study of a poultry trading network in Bangladesh: implications for control and surveillance of avian influenza viruses. BMC Veterinary Research. 14(1): p.12.

OIE. 2018. Update on avian influenza in animals (types H5 and H7). http://www.oie.int/ en/ animal-health-in-the-world/update-onavian-influenza/2018/.

Samad, M.A, Karim, M.R, Islam, Ali, M.Z.... Giasuddin M. 2019.Advent of highly pathogenic avian influenza H5N6 virus in Bangladesh.Proceedings of the 11th International Poultry Show and Seminar, WPSA-BB, 5-6 March, 2019, Dhaka, Bangladesh.

Sarker, R.D., Giasuddin, M., Chowdhury, E.H. and Islam, M.R. 2017. Serological and virological surveillance of avian influenza virus in domestic ducks of the north-east region of Bangladesh. BMC Veterinary Research. 13(1): p.180.

Shin, J.H., Mo, J.S., Kim, J.N., Mo, I.P. and Ha, B.D. 2016.Assessment of the safety and efficacy of low pathogenic avian influenza (H9N2) virus in inactivated oil emulsion vaccine in laying hens. Journal of Veterinary Science. 17(1): 27-34.

World Health Organisation (WHO). http:// www. who.int/csr/don/2012_03_07/ en/ 